\title{
Л.Н. Жукова*
}

\section{К ВОПРОСУ О ПОЯВЛЕНИИ ЖЕЛЕЗНЫХ ИЗДЕЛИЙ И КУЗНЕЧЕСТВА У СЕВЕРНЫХ ЮКАГИРОВ}

\begin{abstract}
В статье анализируются данные из различных источников о появлении первых изделий из железа у колымских юкагиров, привлекаются данные по юкагирам рек Яны, Индигирки, Анадыря. Хронологические рамки исследования охватывают период с конца XVI до конца XIX вв. Источниками нового материала и технологий изготовления предметов из металла для юкагиров являлись якуты, русские, возможно, тунгусы. В середине XVIII в. самые восточные группы юкагиров р. Анадырь уже знали кузнечество, оленные чукчи освоили кузнечество позднее.
\end{abstract}

Ключевые слова: Колымский регион, юкагиры, железные изделия, кузнечество, якуты, русские

On the emergence of iron items and blacksmithing among the northern Yukagirs. LYUDMILA N. ZHUKOVA (Institute for Humanities Research and Indigenous Studies of the North, Siberian Branch of the Russian Academy of Sciences)

The article analyzes the data from various sources on the emergence of the first iron items among the Kolyma Yukagirs, including the facts about the Yukagirs of the Yana, Indigirka and Anadyr rivers. The chronological scope of the study covers the period from the end of the XVI ${ }^{\text {th }}$ to the end of the XIX ${ }^{\text {th }}$ century. New materials and technologies of manufacturing iron items came from the Yakuts, Russians, and possibly the Tungus. In the middle of the XVIII ${ }^{\text {th }}$ century the most eastern Yukagir groups of the Anadyr River already knew blacksmithing, the Reindeer Chukchi mastered blacksmithing later.

Keywords: Kolyma region, Yukagirs, iron products, blacksmiths, Yakuts, Russians

В начале XX в. пионер юкагироведения В.И. Иохельсон писал, что с железом юкагиры познакомились ранее прихода русских на северо-восток Азии: «Древние юкагиры могли приобретать железо у якутов или японцев через курильцев, камчадалов и коряков или у китайцев через тунгусов ... и заимствовали искусство обработки железа не у русских, а у якутов» [12, с. 598-599]. К сожалению, обменные связи юкагиров с названными народами еще мало исследованы.

Сохранилась челобитная русскому царю от известного землепроходца Семена Дежнева с сообщением о том, что в 1640-х гг. в боях с колымскими юкагирами он получил 9 ранений, причем два раза стрелою «железницею» (т.е. с железным наконечником) [15, с. 28]. Однако юкагиры верхней Колымы (или лесные, одуль)

* ЖУКОВА Людмила Николаевна, кандидат исторических наук, старший научный сотрудник отдела археологии и этнографии Института гуманитарных исследований и проблем малочисленных народов Севера Сибирского отделения РАН.

E-mail: zjukova@mail.ru

(C) Жукова Л.Н., 2018 
считали себя народом, до прихода русских не знавшим железа, владевшим только каменными топорами, костяными стрелами и ножами из реберных костей животных [11, с. 105, № 28]. В варианте предания о первой встрече с русскими сообщается, что «юкагиров было весьма много. Среди русских вместе были (т.е. юкагиры объединились. - прим. авт.), взять их (русские) не могли». После того, как часть юкагиров умерла от эпидемии, силы их ослабли. «С русскими побратались, - говорится в предании. - Русские топоров дали. Русские сказали: «Этим дерево рубите». Все начали рубить. Некоторые, свои ноги отрубив, умерли. Свои каменные топоры все бросили. Ножей дали. Разных вещей - все давали» [11, с. 123, № 30].

Из текста следует, что верхнеколымские одулы после некоторого сопротивления («взять их (русские) не могли») «побратались» с русскими, и русские передали юкагирам «разные вещи», особенно отмечены предметы быта из железа - топоры для рубки деревьев и ножи, т.е. это не были предметы вооружения. Начиная с первой половины XVII в. изделия из металла (железо, медь, олово) для обмена на пушнину везли с собой землепроходцы, отправляясь на северо-восток Азии. Так, в 1640 г. из Якутского острога вниз по р. Лене для ясачного сбора отправился московский приказчик Яков Козьмин, кроме муки, воска, сетей, тканей и прочего, он вез «20 цепей собачьих ... 3000 пуговиц оловянных, 70 колокольчиков, 1 пуд олова в блюдях, 1,5 пуда меди красной в котлах, 2 пуда меди зеленой» [19, с. 19].

Расселению якутов на севере Якутии также предшествовали военные столкновения. Об этом повествуют отрывки песенных преданий юкагиров. «Недалеко от нынешнего Адыя (Абыя? - прим. авт.) (р. Индигирка) одулы увидели нечто невиданное и необъяснимое: они увидели белых и черных оленей без рогов с круглыми копытами, с волосатыми до самой земли хвостами. И на этих «оленях», больших, как лоси, ездили верхом люди, вооруженные железными (выделено нами. - прим. авт.) копьями и мечами, которые были гораздо смертоноснее, что копья одулов или их стрелы с костяными и каменными наконечниками. Они поражали всех, кого только увидят. Эти существа, шестиногие, двуглавые, четырехглазые, с длинным хвостом, были все же смертны, ... и юкагиры ... сначала только убивали этих невиданных оленей, т.е. якутских лошадей, считая их главным злом, а на седоков даже не обращали осо- бого внимания. Это и было причиной падения юкагиров и победы и торжества якутов», - писал верхнеколымский юкагир, первый из числа народов Севера к.э.н. Н.И. Спиридонов (Тэки Одулок) [18, с. 23].

Следовательно, еще до прихода русских на северо-восток Азии отдельные группы северных юкагиров узнали о железных боевых изделиях от якутских воинов. Известно, что русские землепроходцы встретили якутов-скотоводов близ устья р. Вилюй, на средней Лене и на р. Яне [16, с. 281], откуда они, видимо, продвигались далее на восток, в частности, на Индигирку, о чем поется в юкагирском предании. На верхней Колыме первые якутские поселения появились после прихода туда русских казаков, следовательно, первые железные изделия верхнеколымские юкагиры не могли получить от якутов.

Надо полагать, что колымские и другие территориальные группы юкагиров, как северные, так и южные, впервые узнали о железе не от пришлых торговцев, а во время военных столкновений. Установлению дружественных, меновых и торговых сношений юкагиров с соседними народами предшествовал период боевых стычек, на что указывается в архивном документе, составленном Семеном Дежневым, и в юкагирском фольклоре. Сообщение С. Дежнева в 1640-х гг. о наличии железных стрел у колымских юкагиров касается, должно быть, северной нижнеколымской группы юкагиров, имевшей ранние контакты с якутами.

Сведения о железных изделиях северные юкагиры могли получить и от тунгусов, на что указывал В.И. Иохельсон. Современные исследователи полагают, что «еще в начале XVII в. между юкагирами и эвенами велась вооруженная межплеменная вражда: эвены расселялись на юкагирские земли и занимали их, юкагиры пытались отстоять свои территории, и в ходе этого процесса происходили ожесточенные столкновения, в которых юкагиры, согласно сообщенным В. Иохельсону преданиям, «преследовали тунгусов как диких зверей», и обе стороны доходили до того, что не щадили даже женщин» [14, с. 39]. Более точных сведений о наличии железных изделий у этих прибывших на север ранних тунгусских групп нет. «Отметим, что приохотские эвены (ламуты), постоянные противники юкагиров в XVII в., в 1651 г., по сообщению русского документа, бились с русскими «збруйны и оружейны, с луки и копья, в куяках и шишаках, в железных и костяных»»» [13, с. 108]. 
А.А. Немировский сделал подборку архивных и литературных данных о железных изделиях, бывших в употреблении у северных юкагиров в первой половине XVII в. Так, «в челобитье Прокопия Краснояра от 1645 г. сказано, что уже в 1642 г. индигирские юкагиры атаковали русских служилых врукопашную не только своим обычным оружием (ножами, копьями, каменными топорами и т.д.), но и «саблями(!)»»» [13, c. 108].

В.И. Иохельсон юкагирской «саблей» называл большой охотничий нож чомо чођойэ, используемый для поколки оленей из челнока, а также для разделывания мяса лося или оленя: это «боевое оружие, в виде короткой сабли, по-якутски называется батас» $[11$, с. 69 , № 17 (прим. 7); 12, с. 603]. Наличие в 1642 г. у индигирских юкагиров железной «сабли» (возможно, якутского батас) явно указывает на то, что оружие было трофейным, полученным в период стычек с иноплеменными воинами.

Особо интересен следующий приведенный в книге архивный документ. В 1649/1650 г. янские юкагиры в составе выплачиваемого русской власти ясака передали служилым людям изделия из металла: «десять куяков [наборных панцирей] якутских да четверы нарушны [наручня], шапку железную [шлем], девять безмен олова, двести восемьдесят семь полиц [пластин] куяшных, две пальмы большие ..., два ножишка руския» [13, с. 109]. Таким образом, янские юкагиры сдали русским в ясак железные изделия преимущественно якутского производства (10 панцирей с 287 отдельными платинами к ним, 4 наручня, 1 шлем, 2 большие пальмы). Вполне возможно, что под названием «большие пальмы» подразумеваются те же якутские сабли батас. Железное боевое снаряжение якутских воинов могло сохраняться янскими юкагирами как трофейное, доставшееся от периода проникновения якутов и защиты юкагирами своих северных территорий. Предполагаемые столкновения происходили в конце XVI - самом начале XVII вв., т.к. по картографической схеме, составленной Г.А. Поповым, на верхней и нижней Яне в 1630-х гг. уже значатся несколько поселений якутов [16, с. 280].

Предметы боевого снаряжения якутов в арсенале юкагиров - железные стрелы, «сабли», панцири - не были массовыми. В русских документах того времени, как показывают приведенные записи, упоминания о них единичны и с некоторым недоумением присутствия железных изделий среди прочего оружия юкаги- ров, изготовленного из природных материалов. В историческом предании алазейских юкагиров о борьбе с соседними чукчами в начале XVII в. сообщается, что юкагирский вождь Эдилвей был облачен в железный панцирь [13, с. 109]. В середине XVII в. «замиренные» янские юкагиры сдали в ясак русским уже потерявшие прежнее значение боевые трофеи.

В перечне 1649/1650 г. в составе выплаченного янскими юкагирами ясака названы «два ножишка руския» и «девять безмен олова» предметы, полученные от русских. Неясны причины включения этих предметов в ясак. Например, группа анадырских юкагиров-ходынцев в начале 1654 г. обещала русским возить их грузы с Анадыря на Анюй в обмен на «железо всякое дельное» (т.е. на всевозможные изделия из железа) [13, с. 109]. В меновой торговле с русскими на меха юкагиры предпочитали другим товарам железо «делное» (т.е. в изделиях) и одекуй (крупный бисер). В качестве «делного» железа привозили в Юкагирскую землю и разобранные на пластины куяхи (доспехи) [15, с. 28].

Во второй половине XVII в. анадырские, верхнеколымские, а также смежных приохотских ареалов юкагирские племена подверглись нападениям другого восточного соседа - коряков. «По разрозненным русским источникам создается впечатление, что в конце 1660-х 1680-х гг. имела место вспышка экспансии коряков... однако после 1690-х гг. такие набеги были существенно затруднены - приохотские коряки, смежные с бассейном Колымы, были довольно прочно объясачены» [13, с. 11]. По-видимому, период примерно в сто лет (конец XVI - конец XVII вв.) для северных юкагиров рек Яны, Индигирки, Алазеи, Колымы, Анадыря был полон драматических событий, связанных с приходом якутских воинов, тунгусов, русских казаков-землепроходцев и коряков. Физические и моральные силы преимущественно охотничье-рыболовных юкагирских племен были истощены в неравной борьбе. С этого времени, нужно думать, начинается физическая и культурная депопуляция северных юкагиров, осложненная государственной ясачной политикой.

Полагаем, что сходные процессы могли происходить и в Южной Якутии, куда на ранних этапах железного века (начало I тыс. н.э.) стали проникать группы иноэтнического населения, вооруженного железным оружием [1]. Группы южных юкагиров и соседствующие с ними иноэтничные племена (носители неолитической 
традиции хоронить умерших в грунтовых могилах, а также оставившие наскальные рисунки позднего неолита - бронзового века, по своему смысловому содержанию не соответствовавшие мировоззренческим установкам древних юкагиров [4; 6; 9]) были разгромлены пришельцами. Одной из причин их поражения являлась архаичность боевого арсенала, изготовленного из природных материалов (камень, кость, рог, дерево). Предполагаемый отход каких-то групп аборигенного населения в западном, северном и восточном направлениях мог осуществляться по ранее известным военно-промысловым, обменным, кочевым родоплеменным маршрутам.

События в южной и центральной Якутии, разделенные временем примерно в 1,5 тыс. лет - появление воинов, вооруженных железным оружием (начало I тыс. н.э.) и казаков с огнестрельным оружием (начало XVII в.), представляют собой два относительно схожих по значимости исторических события, вызвавших стрессовое состояние у населения Якутии и откочевки его с территорий проживания на новые места.

Со второй половины XVII в. с русскими связано более или менее систематическое получение колымскими юкагирами железных изделий. Плательщики ясака юкагиры в XVII-XVIII вв. обычно получали железные изделия в обмен на пушнину, участвуя в казачьих экспедициях в качестве проводников, рекрутировались в походы «на немирных» инородцев и проч. С появлением ввозимых торговыми и промышленными людьми предметов из металла и постепенным развитием собственного юкагирского кузнечества (в XVIII в.) произошло естественное исчезновение традиции использования камня в качестве материала для изготовления боевых и утилитарных предметов. Многие в прошлом изделия из камня были заменены на железные (топоры, ножи, наконечники стрел, копий, дротиков, скребки и проч.), однако количество их было незначительным. В этот период в традиционном инвентаре стали преобладать костяные изделия. Несмотря на это, в конце XX - начале XXI вв. юкагиры продолжали сохранять пережиточное религиозно-магическое отношение к камню как носителю особой природной силы [7].

В середине XVIII в. самые восточные группы юкагиров, проживавшие по р. Анадырь, имели разнообразные изделия из железа и могли его обрабатывать. И.С. Гурвич сделал анализ документа 1754 г. об ограблении оленными чук- чами юкагиров чуванского и ходынского родов на р. Налуче (район р. Анадырь) [3]. В реестре отобранного у юкагиров имущества преобладающее число составляли домашние олени, одежда и металлические изделия. Исследователь писал: «Среди оружия упоминаются железные копья, стрелы железницы, пальмы, железные наручни (кистени), ножи с украшениями в виде оловянных припоев. Следует отметить, что в списке упомянуто значительное число предметов русского производства, по-видимому, приобретенных юкагирами у русских служилых, торговых и промышленных людей. Большую ценность представляли для юкагиров металлические инструменты: топоры, всевозможные пилы, сверла (напари), зубила, палемки кроильные, тюкавки, скобели, молотки, ножницы и т.д... Среди захваченного имущества следует отметить медные и железные котлы, оценивавшиеся от 2 до 21 руб., сковороды, привозные украшения: круги серебряные, наигольники, колокольчики» [3, с. 248-249].

Едва ли юкагирскими или русскими были железные панцирные кольчуги: «У наиболее богатых и знатных юкагиров были кольчуги (куяки) представлявшие, по-видимому, большую ценность и редкость, так как перечень имущества начинался с них» [3, с. 248]. В тексте дважды названы «куяк железный» ценой 16 руб. 50 коп. и 14 руб. 50 коп. По одному разу упоминаются: «шишак железный», «палка железная», «трезуб железный», «тул (колчан) медный».

Опись показывает, что среди отнятых вещей чуванцев и ходынцев у князца Ядачи Соболькова значатся «двои мехи» ценой 1 руб. У Толяха Еремкина - «одне клещи, два молота» общей стоимостью 6 руб. Четыре раза в списке назван «молот однорушный» по цене от 50 коп. до 1 руб. Эта восточная юкагирская группа в середине XVIII в. имела кузнечные меха, клещи, молоты, что является одним из ранних свидетельств появления местного кузнечества.

Из документа 1754 г. следует, что: 1) анадырские юкагиры (чуванцы и ходынцы) были оленеводами, по характеру оленеводства и глухому типу одежды их материальная культура близко примыкала к чукотской и корякской; 2) из описи имущества оленных коряков [2, с. 254], становится ясным, что в середине XVIII в. юкагиры и коряки получали железные изделия от русских, якутов и тунгусов; 3 ) кочевавшие восточнее р. Колымы оленные юкагиры и коряки имели своих кузнецов (умели чинить котлы), пользовались относительно одинаковыми 
железными инструментами (топоры, ножи, палемки и др.) [8].

Якуты сыграли активную роль в распространении железных изделий среди юкагиров, когда расселились по р. Колыме, и якутское купечество приняло участие в сборе ясака и вступило в товарно-денежные отношения с аборигенным населением севера. «Во 2-й пол. ХVШ в. усилилась торговля среди якутов. Появились свои купцы, которые кое-где стали вытеснять русский капитал. [В местную русскую администрацию] стали поступать жалобы русских купцов на «незаконную» торговлю якутов, особенно на севере» [17, с. 35].

Итак, во второй половине XVII-XVIII вв. под влиянием русских, якутов и тунгусов у северных юкагиров получили распространение изде- лия из железа, почти полностью вытеснившие, в первую очередь, предметы из камня. Оленные чукчи, долгое время сопротивлявшиеся местной русской администрации, получали железные изделия чаще всего путем разорительных набегов на ясачных юкагиров и коряков.

В период проведения исследовательских работ В.И. Иохельсона (конец XIX - начало XX вв.) лесные юкагиры имели своего кузнеца, «который делал инструменты и различные изделия не только для своих сородичей, но и для соседей якутов и кочевых тунгусов» [12, с. 597-598]. Юкагирский кузнец мог ремонтировать ружья и копья, делал ножи, топоры и др. (Рис. 1). Однако его изделия были несовершенными и грубыми: ножи и копья, по свидетельству В.И. Иохельсона, отличались гибкостью, были и другие дефекты.

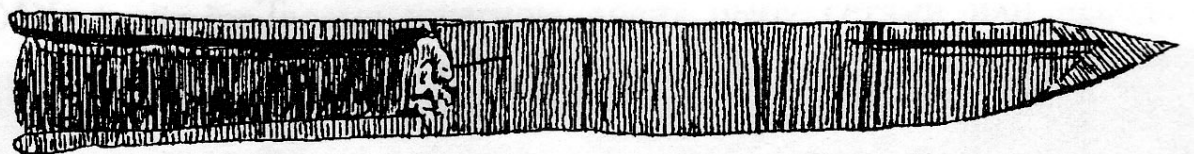

a
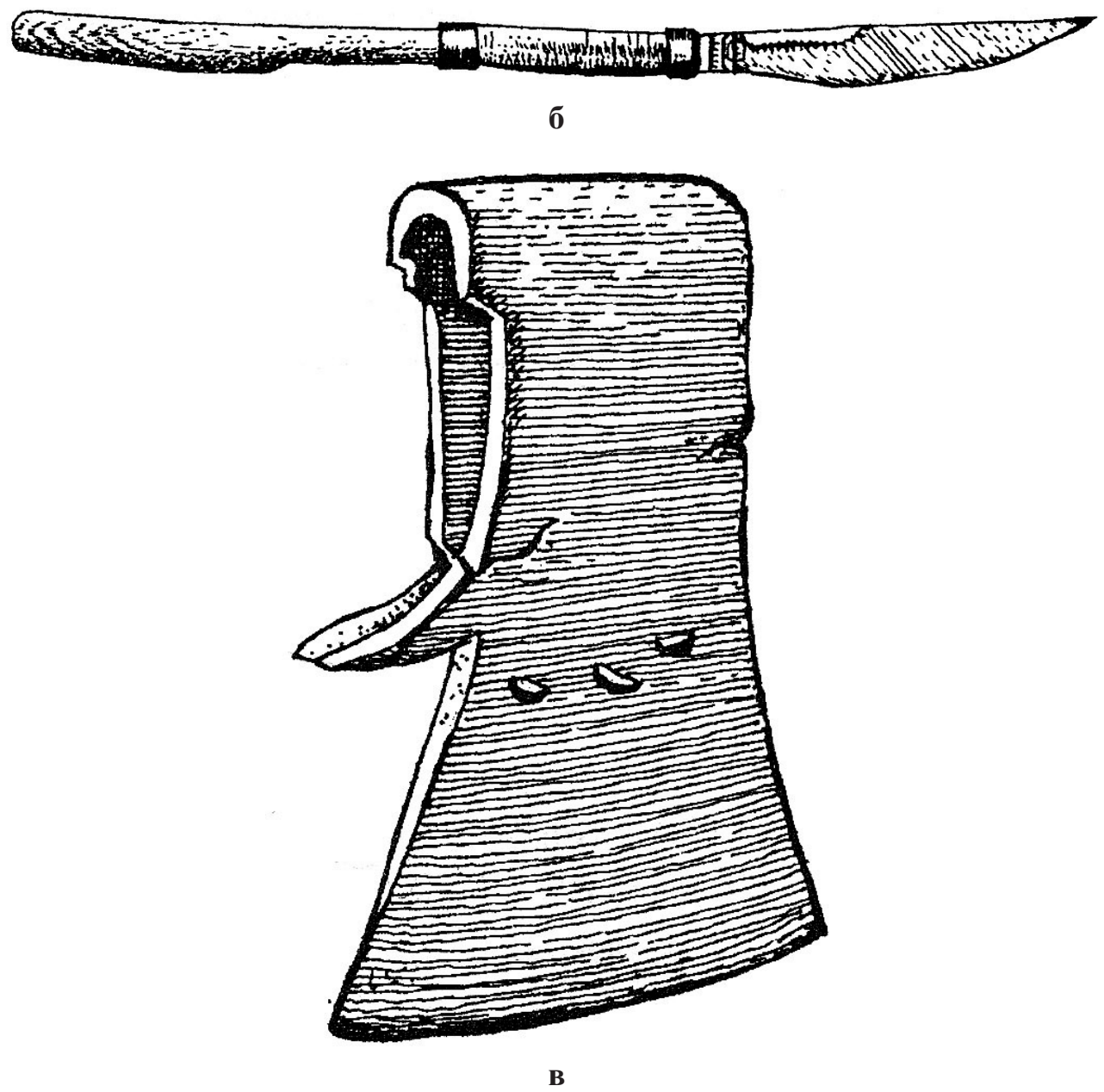

Puc. 1. Предметы из юкагирской коллекции В.И. Иохельсона [12]:

a - железный ледоруб; б - юкагирское копье, которым убивают оленей из челнока; в - топор для рубки деревьев 
В осмотренных исследователем воздушных и наземных захоронениях колымских юкагиров XVIII-XIX вв. многие предметы вооружения и промысла, религии и быта, украшения были изготовлены из природных материалов. Каменные наконечники стрел к концу XIX в. были заменены на костяные и железные, использовались и деревянные. В XVII-XVIII вв. в погребальном комплексе еще могли сочетаться предметы из камня и железа. В.И. Иохельсон при осмотре старинных юкагирских воздушных могил нашел в одной из них (захоронение в колоде на 4-х столбах) каменные и костяные наконечники стрел, а также железное изделие: с левой стороны скелета лежал «наполовину проржавевший длинный воинский нож». Факт нахождения длинного воинского ножа из железа привел исследователя к заключению о том, что захоронение совершено после прибытия на Колыму «якутов, или, возможно, даже русских» [12, с. 312]. В этом мужском воздушном захоронении сочетаются древние (каменные наконечники стрел) и новые привнесенные (железный воинский нож) элементы. Отсутствие железных изделий в юкагирских могилах объясняется также традицией не класть с покойником железных изделий, которые отягощают «путника» в дороге.

В завершении исследования подведем некоторые итоги.

1. В районе р. Колымы и рек северо-востока Якутии археологические памятники начала I тыс. н.э., содержащие железные изделия, не обнаружены. Карта-схема распространения памятников раннего железного века в Якутии показывает, что носители культуры железного века двигались по южной и центральной Якутии в широтном направлении с востока на запад и вниз по р. Лене [1, с. 17].

2. Первые известия о железе некоторые группы северных юкагиров получили от якутов (и тунгусов?) в конце XVI - начале XVII в., еще до прихода русских казаков на северо-восток Азии.

3. Первые железные изделия появились у колымских юкагиров в виде боевых трофеев, позднее - как подарки от пришельцев (якуты, русские). В результате иноэтничных заимствований появилось кузнечество и собственные кузнецы. На железо могли быть перенесены отдельные автохтонные формы каменных и костяных изделий (середина XVIII-XIX вв.) [5; 10].

4. В распространении железных изделий можно выделить три этапа: начальный - появ- ление боевых предметов в результате проникновенийиных этносов, набегов с целью захвата имущества, женщин, территорий. Второй период - обменные контакты. Третий период - хозяйственно-культурные контакты. В этот период происходит освоение техники обработки металла.

5. Межэтнические контакты на северо-востоке Якутии в середине II тыс. н.э. (юкагиры, якуты, тунгусы, русские, коряки) способствовали разнообразию инвентаря, в том числе из металла.

\section{СПИСОК ЛИТЕРАТУРЫ}

1. Алексеев А.Н. Древняя Якутия: железный век и эпоха средневековья. Новосибирск: Издво ИАиЭ СО РАН, 1996.

2. Вдовин И.С. Очерки этнической истории коряков. Л.: Наука, 1973.

3. Гурвич И.С. Юкагиры чуванского рода в середине XVIII в. // Сибирский этнографический сборник. Т. 35. М.-Л.: Изд-во АН СССР, 1957. С. 246-262.

4. Жукова Л.Н. Очерки по юкагирской культуре. Ч. 2. Новосибирск: Наука, 2012.

5. Жукова Л.Н. Феномен «якутского» ножа // Очерки по юкагирской культуре. Ч. 3. (Из ранее опубликованного). Якутск: Бичик, 2013. С. 71-79.

6. Жукова Л.Н. Древние грунтовые погребения р. Колымы (палеоэтнографический анализ) // Homo Eurasicus в системах социальных коммуникаций. Материалы VI Всероссийской научно-практической конференции. Санкт-Петербург, 26 октября 2015. М.-Берлин: Директ-Медиа, 2015. С. 317-342.

7. Жукова Л.Н. Значение гальки и камня в традиционной культуре колымских юкагиров // Гуманитарные исследования в Восточной Сибири и на Дальнем Востоке. 2015. № 3. С. 15-20.

8. Жукова Л.Н. Материальная культура юкагиров-чуванцев (По архивному документу XVIII в.) // Якутский архив. 2015. № 1. С. 16-20.

9. Жукова Л.Н. Неолитическое погребение Каменка II на Средней Колыме (палеоэтнографический анализ) // Северо-Восточный гуманитарный вестник. 2015. № 3. С. 19-26.

10. Жукова Л.Н. Традиционные формы ножей аборигенного населения Колымы и Чукотки: от каменной индустрии к изделиям из железа // Гуманитарные исследования в Восточной Сибири и на Дальнем Востоке. 2017. №4. С. 22-28.

11. Иохельсон В.И. Материалы по изучению юкагирского языка и фольклора, собранные в Колымском округе. Якутск: Бичик, 2005. 
12. Иохельсон В.И. Юкагиры и юкагиризированные тунгусы / пер. с англ. В.Х. Иванова и 3.И. Ивановой-Унаровой. Новосибирск: Наука, 2005.

13. Немировский А.А., Прокопьева П.Е. Материалы для изучения эпоса о Халандине. М.: «Буки Веди», 2017.

14. Немировский А.А., Прокопьева П.Е., Жукова Л.Н. «Грабить не для себя»: мотив юкагирского эпоса о Халандине в историко-культурном контексте // Северо-Восточный гуманитарный вестник. 2018. № 1. С. 36-40.

15. Огородников В.И. Из истории покорения Сибири: Покорение юкагирской земли // Труды Университета народного образования в Чите. Кн. 1. Чита, 1922.

16. Попов Г.А. Расселение якутов в XVII и XVIII ст. // Сочинения. Т. 2. Якутск, 2006. C. 278-288.

17. Попов Г.А. К истории национально-буржуазного движения в Якутии до революции // Сочинения. Т. 6. Якутск, 2016. С. 11-72.

18. Спиридонов Н.И. (Тэки Одулок). Одулы (юкагиры) Колымского округа. Якутск: Северовед, 1996.

19. Явловский П.П. Летопись города Якутска от основания его до настоящего времени. Т. 1. Якутск: Якутский край, 2002.

\section{REFERENCES}

1. Alekseev, A.N., 1996. Drevnyaya Yakutiya: zhelezniy vek i epokha srednevekov'ya [Ancient Yakutia: the Iron Age and the Middle Ages]. Novosibirsk: Izd-vo IAiE SO RAN. (in Russ.)

2. Vdovin, I.S., 1973. Ocherki etnicheskoy istorii koryakov [Essays on the ethnic history of the Koryaks]. Leningrad: Nauka. (in Russ.)

3. Gurvich, I.S., 1957. Yukagiry chuvanskogo roda $\mathrm{v}$ seredine XVIII v. [The Yukagirs of the Chuvan family in the middle of the XVIII century]. In: Sibirskiy ehtnograficheskiy sbornik. T. 35. Moskva-Leningrad: Izd-vo AN SSSR, pp. 246262. (in Russ.)

4. Zhukova, L.N., 2012. Ocherki po yukagirskoy kul'ture. Ch. 2 [Essays on the Yukagir culture. Part 2]. Novosibirsk: Nauka. (in Russ.)

5. Zhukova, L.N., 2013. Fenomen «yakutskogo» nozha [The phenomenon of the "Yakut» knife]. In: Ocherki po yukagirskoy kul'ture. Ch. 3. (Iz ranee opublikovannogo). Yakutsk: Bichik, pp. 71-79. (in Russ.)

6. Zhukova, L.N., 2015. Drevnie gruntovye pogrebeniya r. Kolymy (paleoetnograficheskiy analiz) [Ancient soil burials of the Kolyma river (paleoethnographic analysis)]. In: Homo Eurasicus v sistemakh sotsialnykh kommunikatsiy. Materialy VI Vserossiyskoy nauchno-prakticheskoy konferentsii. Sankt-Peterburg, 26 oktyabrya 2015. MoskvaBerlin: Direkt-Media, pp. 317-342. (in Russ.)

7. Zhukova, L.N., 2015. Znachenie gal'ki i kamnya $\mathrm{v}$ traditsionnoy kul'ture kolymskikh yukagirov [The meaning of pebble and stone in the traditional culture of Kolyma Yukagirs], Gumanitarnye issledovaniya v Vostochnoy Sibiri i na Dal'nem Vostoke, no. 3, pp. 15-20. (in Russ.)

8. Zhukova, L.N., 2015. Material'naya kul'tura yukagirov-chuvantsev (Po arkhivnomu dokumentu XVIII v.) [The material culture of the Chuvans (according to the archival document of the 18th century)], Yakutskiy arkhiv, no. 1, pp. 16-20. (in Russ.)

9. Zhukova, L.N., 2015. Neoliticheskoe pogrebenie Kamenka II na Sredney Kolyme (paleoetnograficheskiy analiz) [Neolithic burial Kamenka II on the Middle Kolyma river (paleoethnographic analysis)], Severo-Vostochniy gumanitamiy vestnik, no. 3, pp. 19-26. (in Russ.)

10. Zhukova, L.N., 2017. Traditsionnye formy nozhey aborigennogo naseleniya Kolymy i Chukotki: ot kamennoy industrii $\mathrm{k}$ izdeliyam iz zheleza [Traditional forms of knives among the indigenous population of Kolyma and Chukotka: from stone to iron items], Gumanitarnye issledovaniya $\mathrm{V}$ Vostochnoy Sibiri i na Dal'nem Vostoke, no. 4, pp. 22-28. (in Russ.)

11. Jochelson, V.I., 2005. Materialy po izucheniyu yukagirskogo yazyka i fol'klora, sobrannye v Kolymskom okruge [Materials on Yukagir language and folklore, collected in the Kolyma district]. Yakutsk: Bichik. (in Russ.)

12. Jochelson, V.I., 2005. Yukagiry i yukagirizirovannye tungusy [Yukagir and Yukagirized Tungus]. Novosibirsk: Nauka. (in Russ.)

13. Nemirovsky, A.A. and Prokopieva, P.E., 2017. Materialy dlya izucheniya eposa o Khalandine [Materials for studying the epic about Khalandin]. Moskva: «Buki Vedi». (in Russ.)

14. Nemirovsky, A.A., Prokopieva, P.E. and Zhukova, L.N., 2018. "Grabit' ne dlya sebya»: motiv yukagirskogo eposa o Khalandine $\mathrm{v}$ istoriko-kul'turnom kontekste [«To plunder not for oneself»: the motif of the Yukagir epic about Khalandin in the historical and cultural context], Severo-Vostochnyy gumanitarnyy vestnik, no. 1, pp. 36-40. (in Russ.)

15. Ogorodnikov, V.I., 1922. Iz istorii pokoreniya Sibiri: Pokorenie yukagirskoy zemli [From the 
history of conquest of Siberia: the conquest of the Yukagir land]. In: Trudy Universiteta narodnogo obrazovaniya v Chite. Kn. 1. Chita. (in Russ.)

16. Popov, G.A., 2006. Rasselenie yakutov v XVII i XVIII st. [The settlement of the Yakuts in the XVII and XVIII centuries]. In: Popov, G.A., 2006. Sochineniya. T. 2. Yakutsk, pp. 278-288. (in Russ.)

17. Popov, G.A., 2016. K istorii natsional'noburzhuaznogo dvizheniya $\mathrm{v}$ Yakutii do revolyutsii [To the history of the national-bourgeois movement in Yakutia before the revolution]. In: Popov, G.A., 2016. Sochineniya. T. 6. Yakutsk, pp. 11-72. (in Russ.)

18. Spiridonov, N.I., 1996. Oduly (yukagiry) Kolymskogo okruga [Oduls (Yukagirs) of the Kolyma district]. Yakutsk: Severoved. (in Russ.)

19. Yavlovskiy, P.P., 2002. Letopis' goroda Yakutska ot osnovaniya ego do nastoyashchego vremeni. T. 1 [Chronicle of the city of Yakutsk from its foundation to the present day. Vol. 1]. Yakutsk: Yakutskiy krai. (in Russ.)

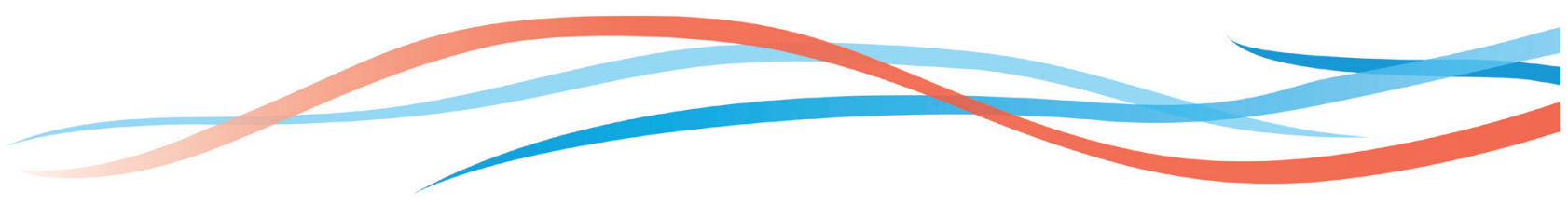

